Research Article

\title{
Prevalence of Hypertension and its Associated Factors among Retired Army in Pokhara
}

${ }^{1}$ Shreena Ranjitkar, ${ }^{2}$ Sunita Sharma*

${ }^{1,2}$ School of Health and Allied Sciences, Pokhara University

*Corresponding email: sharmasunu789@gmail.com

\author{
Article History \\ Received 23 March 2021 \\ Revised 10 October 2021 \\ Accepted 10 November 2021
}

\begin{abstract}
Hypertension can be caused by a number of factors. Tobacco usage, excessive alcohol use, a poor diet, high salt intake, overweight and obesity, and physical inactivity are among these factors. Demographic factors such as age, ethnicity and family history also play a role in causing hypertension. When inherited factors are paired with an unhealthy lifestyle, the chance of high blood pressure rises. A cross-sectional descriptive research design was used for this study. Non probability purposive sampling was done to select the sample. Three hundred and fifteen retired army were chosen as a sample. Semi-structured interview schedule was used to collect data. Over all prevalence of hypertension was 58.41\% with newly diagnosed cases of 33(10.4\%) and previous cases of 151(47.9\%) and this was significantly associated with Age, years of retirement, smoking, chewing tobacco and salt consumption. The burden of hypertension was high, and it has become a major health concern among retired army. To deal with life-threatening consequences and chronic debilitating morbidity, a community screening program, timely detection, lifestyle adjustment, treatment, and prevention are all critical.
\end{abstract}

Keywords: Body mass index, hypertension, obesity, prevalence, retired army, smoking, waist hip ratio.

\section{INTRODUCTION}

According to World Health Organization [WHO], normal adult blood pressure is defined as a systolic blood pressure of $120 \mathrm{mmHg}$ and a diastolic blood pressure of $80 \mathrm{mmHg}$. Hypertension or high blood pressure is defined as a systolic blood pressure equal to or above

(C) The Author, published by JRCC, Janapriya Multiple Campus. 
$140 \mathrm{mmHg}$ and/or a diastolic blood pressure equal to or above $90 \mathrm{mmHg}$ (World Health Organization, 2013).

Hypertension is major global public health problem. Every year, nearly 8 million people are killed by high blood pressure. Over 1 billion people worldwide suffer from excessive blood pressure. In 2008, the global prevalence of high blood pressure in adults aged 25 and up was around 40.0 percent (including those under medication). The African Region had the highest prevalence of high blood pressure (46.0\%) among all WHO regions in the same year, while the Americas region had the lowest (35.0\%). High blood pressure affects two out of every five persons in the Eastern Mediterranean region. In practically every country in the region, males have higher blood pressure than females (WHO, 2013).

Among South Asian countries, Nepal reported the highest proportion of hypertensive people (33.8\%). In Nepal, hypertension is prevalent in $17.0 \%$ of women and $23.0 \%$ of men age 15 and above. In age group of $55-59$ years, $32.0 \%$ of women and $36 \%$ of men have hypertension. It is most likely to be hypertensive if you belong to the criteria of women and men in urban areas, those living in the Hill ecological zone, in the Western region (WHO, 2013).

Nepal is currently undergoing an epidemiological change, which is accompanied by an increase in the burden of non-communicable diseases. According to several research, the prevalence of hypertension among Nepalese people ranges from 21.0 percent to 34.0 percent. Two cross-sectional studies conducted in a rural part of the Kathmandu valley indicated that the number of hypertension increased about thrice in those aged 21 and above over a 25 -year period from 1981 to 2006.

The link between salt intake and hypertension has been recognized for about 60 years, and it also applies to indigenous. We found a higher burden of hypertension among people who consume more than 10 grams of salt per day, indicating a link between salt intake and hypertension; as salt intake rises, blood pressure rises as well. (Chakma, 2017). It is therefore, necessary to conduct the study among the retired army. The main objective of this study is to assess the prevalence of hypertension and associated factor among the retired army.

\section{DATA AND METHODS}

A cross sectional descriptive study was carried out among 315 retired army residing in Rambazar 10 and 15, Pokhara, Kaski to find out the prevalence of hypertension among them. The locality consists of residence of retired armies that made feasible for present study. Research 
instrument was validated by incorporating the feedback of subject experts and pretesting was done among of $10 \%$ of total sample size. Information on socio demographic variables and behavioral risk factors were collected, that is, tobacco use, alcohol use, and related factors. Some items in Interview schedule was adopted from World Health Organization's validated STEPS instrument version 3.1, an approach to chronic disease risk factors surveillance measures.

Non probability sampling technique was used to select the sample population. Primary data were collected by face to face interview using semi-structured interview schedule and physical measurement such as height, weight, hip and waist ratio and blood pressure measurement was also done by the help of sphygmomanometer during data collection. Respondents were informed about the purposes and objectives of the study. Informed verbal and written consent was taken from each respondents.

Respondents whose blood pressure were found more than normal range were referred to higher center and advised to consult with the physician. The collected data was coded and entered in Microsoft sciences (SPSS) software version 16 for analysis. Descriptive data was analyzed using mean, frequency, percentage and chi-square test was used to find out the association between hypertension and its risk factors.

\section{RESULTS AND DISCUSSION}

\section{Background Characteristics of Respondents}

Table 1 depicts the background information of the study participants. Just more than half (58.1\%) of the participants were below mean age 64 years. Most of the respondents were the followers of Hindu religion i.e. 309 (97.1\%) and remaining (2.8\%) were Non Hindus. Number of relatively advantaged Janajati were higher i.e. 167 (53.0\%), fewer were Dalit i.e. 10 (3.2\%).

\section{Table 1}

Socio-Demographic Information of Respondents $(n=315)$

\begin{tabular}{lll}
\hline Characteristics & Frequency(n) & Percentage (\%) \\
\hline Age & & \\
Below 64(inclusive) & 183 & 58.1 \\
Above 64 & 132 & 41.9 \\
Religion & & \\
Hindu & 306 & 97.2 \\
\hline
\end{tabular}




\begin{tabular}{|c|c|c|}
\hline Non Hindu & 9 & 2.8 \\
\hline \multicolumn{3}{|l|}{ Ethnicity } \\
\hline Dalit & 18 & 5.7 \\
\hline Disadvantaged Janajati & 16 & 5.0 \\
\hline Disadvantaged non Dalit Terai caste group & 8 & 2.5 \\
\hline Upper caste groups & 96 & 30.7 \\
\hline Relatively advantaged Janajati & 177 & 56.1 \\
\hline \multicolumn{3}{|l|}{ Years of service } \\
\hline Below 23 (inclusive) & 180 & 57.1 \\
\hline Above 23 & 135 & 42.9 \\
\hline \multicolumn{3}{|l|}{ Years of retirement } \\
\hline Below 23 (inclusive) & 177 & 56.2 \\
\hline Above 23 & 138 & 43.2 \\
\hline \multicolumn{3}{|l|}{ Duration suffering from HTN $(n=151)$} \\
\hline Less than 11(including 11) & 133 & 42.2 \\
\hline More than 11 & 18 & 5.7 \\
\hline \multicolumn{3}{|l|}{ Under Medication, $(n=151)$} \\
\hline Yes & 133 & 42.2 \\
\hline No & 18 & 5.7 \\
\hline \multicolumn{3}{|l|}{ Reason for not taking medicine $(n=18)$} \\
\hline Medicine need to be taken regularly & 5 & 27.8 \\
\hline Wish to control with life style change & 10 & 55.6 \\
\hline Controlled BP & 2 & 11.1 \\
\hline Swelling & 1 & 5.5 \\
\hline \multicolumn{3}{|l|}{ Family History of HTN } \\
\hline Yes & 64 & 20.3 \\
\hline \multicolumn{3}{|l|}{ Presence of associated disease } \\
\hline No & 251 & 79.7 \\
\hline Yes & 104 & 33 \\
\hline No & 211 & 67 \\
\hline \multicolumn{3}{|l|}{ Associated disease beyond HTN $(n=69)$} \\
\hline Diabetes & 31 & 44.9 \\
\hline Cardiac disease & 19 & 27.5 \\
\hline Renal Problem & 3 & 4.3 \\
\hline Asthma & 5 & 7.2 \\
\hline
\end{tabular}




\begin{tabular}{lll}
\hline Others & 11 & 15.9 \\
Mental stress & & \\
Yes & 8 & 2.5 \\
No & 307 & 97.5 \\
\hline
\end{tabular}

Table 2 presents the information of respondents. Among 151 cases, $(5.70 \%)$ seems to have chronic hypertension, diagnosed since 11 years. Forty-two percent were under medication and $(5.70 \%)$ were not taking medicine even after diagnosed with HTN. Whereas the reason explained by respondents for not taking medicines is willing to control hypertension by behavior modification.

\section{Table 2}

Prevalence of Hypertension $(n=315)$

\begin{tabular}{lcl}
\hline Characteristics & Frequency & Percentage (\%) \\
\hline Prevalence of HTN & & \\
Hypertensive & 184 & 58.3 \\
Non-hypertensive & 131 & 41.7 \\
\hline
\end{tabular}

Table 3 presents the total prevalence of hypertension. Among 315 respondents, majority (58.3\%) of the respondents had suffered from hypertension whereas $41.7 \%$ were non hypertensive.

\section{Table 3}

Behavioral Information of Respondents $(n=315)$

\begin{tabular}{lll}
\hline Risk factors & Frequency & Percentage (\%) \\
\hline Do you smoke & 117 & 37.1 \\
Yes & 198 & 62.9 \\
No & & \\
Frequency of smoking (n=117) & 97 & 82.9 \\
Daily & 20 & 12 \\
2-4 days a week & & \\
chewing tobacco & 101 & 20.3 \\
Yes & 214 & 79.7 \\
No & & \\
Frequency of chewing tobacco $(\mathbf{n}=\mathbf{1 0 1})$ & 87 & 86.1 \\
Daily & 14 & 13.9 \\
2-4 days a week & & \\
Drink alcohol & 225 & 71.4 \\
Yes & 90 & 28.6 \\
No & & \\
\hline
\end{tabular}


Frequency of drinking alcohol $(n=225)$

Daily

156

69.3

2-4 days a week

55

42.4

Once a week

14

6.2

How much salt you add

1 spoon

87

27.8

Half spoon

136

43.5

One fourth

61

19.5

Pinch of finger

25

7.3

More than 1 spoon

6

1.9

Consumption of processed foods

Always

5

1.6

Sometimes

106

33.7

Rarely

80

25.4

Never

124

39.4

Fruits

Daily

154

48.9

2-4 days a week

131

41.6

Once a week

30

9.5

BMI

Underweight

4

Healthy

Over weight

Obese

52

16.5

WHR

No

41

13.0

Moderate

164

52.1

High

110

34.9

Regular health check ups

Yes

No

185

58.7

Frequency of checkups $(n=130)$

Monthly

3 monthly

6 monthly 


\begin{tabular}{lcc}
\hline Yearly & 17 & 13.1 \\
Others & 20 & 15.4 \\
Do you exercise & & \\
Yes & 292 & 92.7 \\
No & 23 & 7.3 \\
Type of exercise & & \\
Moderate & 244 & 83.6 \\
Vigorous & 48 & 16.4 \\
How many days do exercise (292) & & \\
Daily & 178 & 61.0 \\
2-4 days a week & 106 & 45.3 \\
once a week & 8 & 2.7 \\
Exercise, hours per day (292) & & \\
Less than 1 hour & 96 & 32.9 \\
1-4 hours & & 176 \\
5-8 hours & 15 & 4.8 \\
More than 8 hours & 5 & 1.6 \\
\hline
\end{tabular}

Table 4 depicts that (37.1\%) of the sample population were smokers whereas about one third of the participant chew tobacco. Likewise, $82.9 \%$ of respondents used smoke daily. Majority (71.4\%) of the participants were alcohol users. More than half (58.7\%) go for regular checkups and 41(31.5\%) of them go for monthly checkups. Most $(92.7 \%)$ of the respondent perform physical exercises and larger part $244(83.6 \%)$ of them perform moderate exercise. Maximum respondents (60.2\%) perform exercise for 1-4 hours.

\section{Table 4}

Association Between Socio-Demographic Factors and Hypertension $(n=315)$

\begin{tabular}{llll}
\hline Variables & $\begin{array}{l}\text { Hypertension } \\
\text { Yes }\end{array}$ & No & \\
\hline Age & & & \\
below 64(inclusive) & 62 & 121 & $34.575^{*}$ \\
above 64 & 89 & 43 & \\
Years of retirement & & & \\
Below 23(inclusive) & 67 & 110 & $16.460^{*}$ \\
Above 23 & 84 & 54 & \\
\hline
\end{tabular}

$* \mathrm{p}<0.001$ 
Table 5 presents the statistical significant association between age and years of retirement with hypertension.

\section{Table 5}

Association Between Behavioral Factors and Hypertension $(n=315)$

\begin{tabular}{llll}
\hline Variables & \multicolumn{2}{l}{ Hypertension } & $\chi^{2}$ \\
\hline Smoking & & No & \\
Yes & 73 & 44 & $15.587^{*}$ \\
No & 78 & 120 & \\
Chewing tobacco & & & \\
Yes & 63 & 38 & $12.420^{*}$ \\
No & 88 & 126 & \\
Salt consumption & & & \\
1 table spoon & 119 & 101 & $12.492^{*}$ \\
Less than 1 table spoon & 30 & 63 & \\
Consumption of Fruits & & & \\
Daily & 66 & 88 & $7.508^{* *}$ \\
2-4 days a week & 64 & 67 & \\
Once a week & 21 & 9 & $12.706^{*}$ \\
BMI & & & \\
Not obese & 114 & 149 & \\
Obese & 36 & 15 & \\
\hline
\end{tabular}

$* \mathrm{p}<0.001,{ }^{*} \mathrm{p}<0.05$

Table 5 depicts that there is significant association between smoking, chewing tobacco, salt consumption, consumption of fruits and BMI with Hypertension. It is evident that there smoking, chewing tobacco, consumption and BMI have significant association with hypertension.

\section{CONCLUSION}

The study concluded that more than half of the retired armies were suffered from hypertension. Hypertension is significantly associated with five factors that is age, period retired from army (in years), smoking, chewing tobacco, amount of salt intake. The burden of hypertension is higher among retired army. This result might be the consequences of inactive life style after retirement. Hence, it is essential to emphasize on the public awareness program related to hypertension, risk factors and regular health checkup of the retired army. 


\section{REFERENCES}

Agrawal, N., Bista, B., Bhattarai, S., Dhimal, M., Dixit, L.P., Hyder, M.K., Jha, A. K., \& Rani, M. (2020). Report of non-communicable disease risk factors STEPS survey Nepal 2019. Nepal Health Research Council.

Alurkar, V. M., Kafle, R. C., Paudel. N., Sapkota, S., \& Sharma, D. (2018). Prevalence and associated risk factors of hypertension in rural community of western Nepal: A cross sectional study, Journal of Advances in Internal Medicine 7 (1), 11.

Asresahegn, H., Beyene, E., \& Tadesse, F. (2017). Prevalence and associated factors of hypertension among adults in Ethiopia: A community based cross-sectional study. BMC Research Notes, 10 (1), 629.

Bista, B.,Devkota, S., Dhungana, RR., Joshi, S.,\&Pandey, AR.(2016).Prevalenceandassociated factors of hypertension: A community-based cross-sectional study in municipalities of Kathmandu, Nepal [Internet]. International Journal of Hypertension. [cited 2019 Jul 30]. Available from: https://www.hindawi.com/journals/ijhy/2016/1656938/

Chakma, T., Kavishwar, A., Rao, PV., \& Sharma, R.K. (2017). High prevalence of hypertension and its selected risk factors among adult tribal population in central India. Pathog Glob Health,111 (7), 343-50.

Chawla, S., Jain, S., Jeet, G., Thakur, J.S., \& Tripathy, J.P. (2017). Alarmingly high prevalence of hypertension and pre-hypertension in North India-results from a large cross-sectional STEPS survey. PLoS ONE, (12), e0188619.

WHO (2013). High blood pressure: A public health problem World Health Day. World Health Days [Internet]. [cited 2019 Aug 3]. Available from: http://www.emro.who.int/media/ world-health-day/public-health-problem-factshevet-2013.html 